\title{
Partial Intersection and Discrepancy of Concepts in Cross-Cultural Communication
}

\author{
Narine Harutyunyan \\ Yerevan State University
}

erving as basic supporting elements of the language, concepts unite representa-

$\checkmark$ tives of a certain linguoculture, providing foundation for mutual understanding between them through "bundles of meaning", in which the spirit of the nation is embodied. The conceptual space of a separate language individual and linguoculture as a whole are organized into a concept-sphere, the main characteristics of which are those possibilities of joint "meaning-making" that it opens up before the native speakers.

We believe that the most effective way of "reading" the national-specific concepts from languages is their interlinguistic comparison. One can agree with V.I. Karasik, who deems it possible to present the ethnocultural specifics of concepts by means of "mapping corresponding lexical and phraseological groups, comparing value judgments ensuing form stereotypes of behavior fixed in the meanings of words, set expressions, precedent texts," as well as by means of the analysis of the inner form of words (Karasik 1996:14).

The ability of concepts to grow and enrich due to the individual emotional and cultural experience of native speakers conditions their elasticity, instability, and mobility. On the one hand, the dynamic nature of concepts impedes their "docking" between different cultures. On the other hand, the circumstance that they "spill over" one another forming a united space of culture creates the possibility for creative flight and search for a "compromise" between non-coincident concepts of different linguocultures.

Typical examples of the linguistic embodiment of the comparable but not coinciding concepts of two linguocultures are words that are traditionally used as equivalents, but at the same time they only partially intersect from the point of view of the content inherent in them.

As an example we can point out a discrepancy between the American and Armenian concepts friend and pilitp. For an American the word friend is applicable to any person who is not an enemy. This reflects the unwillingness of Americans to establish very deep and long-term relationship, which is often accounted for by their individualism and geographic mobility. We, on our part, are much "pickier" with respect to who we can call a friend. Armenians feel they can count on a friend for assistance at any time. In the United States, the word friend is used loosely to include acquaintances, which is confusing to Armenians. For us, Armenians, a friend signifies a much closer relationship than it does for the Americans. According to the two Armenian proverbs given below, "death with a friend is a feast" or "friends are better than hundreds of dollars".

Calknnyh viuhn huпuшahp t:

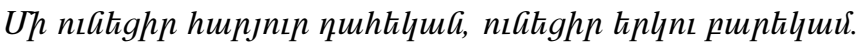


Another example is the English word fun, which with a big stretch can be translated as nınuһnıрјnıG, qципбиGр, nevertheless has a wider semantics; it can stand for any positive emotions and refer to virtually any type of activity. Are you having any fun? is a capacious phrase from Broadway musical "George White's Scandals of 1939" full of irony and at times even sarcasm, and virtually not translatable into Armenian. The

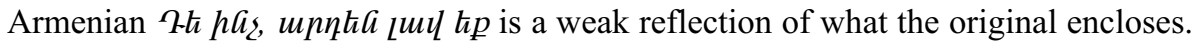

When comparing American and Armenian concept spheres, one thing that calls for attention is that Armenian concepts referring to the spiritual and emotional side of life often do not have American analogues. At the same time American concepts not translatable into Armenian mainly reflect the pragmatic and activist nature of the American culture.

We can oppose the concepts soul and self as key notions characterizing the Armenian and American personality. In the US the presentation of a self is the preferred form of communication activity, indicating personal experience, thoughts and feelings, which is considered to be an adequate way of self-expression. The self is something internal and unique, valued in the society and implicitly suggesting the dignity of both the speaker and the interlocutor.

The former Soviet concept of the self linked with dimensions of individualism-collectivism. It is well-known, that individualists give priority to personal goals over the goals of collectivists. Such traditional vital orientation stimulates a person's practical efforts and aspirations, which are associated with individual success and with the American popular symbol and hero - the self-made man. This concept can be illustrated with the help of the following phraseological units:

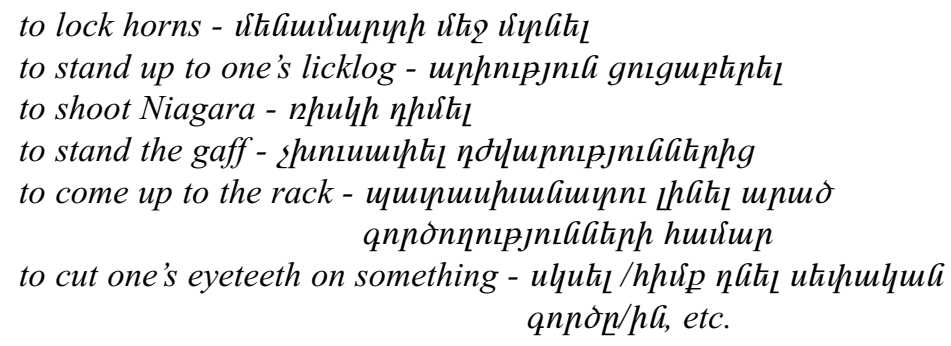

The number of words found in any American English dictionary that are compounded with the word self is the indicator of how American English reflects individualism. One is likely to find in any English dictionary no fewer than 150 such words, including: self-absorbed, self-appointed, self-centered, self-confident, self-supporting, etc. (Cambridge International Dictionary of English 1995). In Armenian culture cordiality and warmth of feeling are more predominant than the individuality. That is why in Malxhasiants' dictionary (1944) one can find approximately 200 compounded words

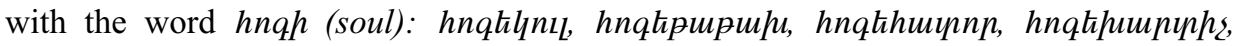
hnqkinn, hnqkipnil, etc.

In the Armenian discourse, one of the main dimensions of interpersonal communica- 
tion is the cordial talk. Thus, on the one hand, there is the "soul" community in which communication is based on the notions of morality and ethics of social life; on the other hand, there is a group of individuals, and factual information revealing their personal experience of interacting with the society lies in the basis of their communication. As a result, Armenians often perceive Americans as "soulless," and Americans think we do not possess enough analytical thinking skills and ability to use factual information.

As a parallel to the concept of hnqh (soul) one may single out the African-American concept of "soul," significantly differing from the Anglo-Saxon concept and signifying deep sincerity, cordiality, and emotionality inherent in the black culture. This concept, which does not coincide with the Armenian one, can nevertheless be compared to it in terms of emotional richness and depth. Its "sphere of influence" includes such notions as soul brother - a black person, the same goes for soul sister (speaking of a girl or a woman), and soul music, a variety of the "rhythm-and-blues" trend that contains elements of black spirituals and is characterized by distinct rhythm and emotionally rich vocal (Leontovich, Sheigal 2000). However, the "aura" of Armenian and the AfricanAmerican concepts and the cultural associations evoked by them are very different and can be compared only to explain the "cordiality" typical of them.

If there was a need to single out key American concepts, one could suggest challenge and privacy, the intranslatability of which into Armenian is obvious.

In the dictionary "Life and Culture of the USA" (2002) the concept challenge, basically having no analogue in Armenian concept sphere, is explained as follows:

1. task 2. problem, difficulty 3. trial 4. defiance . defiance (ukihuluma nudhnh

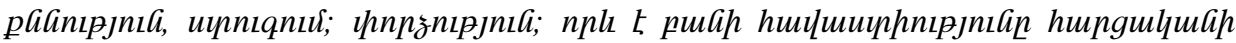

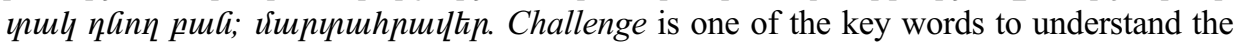
American national character; it expresses courage, readiness to take risks in order to test oneself, the spirit of adventure, striving to compete, and so on. It is not without reason that the name "Challenger" was given to an American spaceship. For example even the simplest sentences Spoke about your sufferings and challenges or We are anchored in one of the most challenged but spirited cities in the USA are hard to translate into Armenian. And its more difficult for us to catch the meaning of the word challenge in connection with political correctness, for example, challenged (instead of disabled, crippled), or a physically challenged person (instead of invalid) and visually challenged (instead of sightless). Adventurism and ability to take risks are more inherent in Americans than in Armenians.

The concept privacy, meaning private space as well as the right for the non-intrusion into private life, occupies an important place in the system of American values and is manifested in all spheres of life: relations between children and parents, teachers and students, colleagues and acquaintances. Let me bring an example about privacy from American scholar Lurie's article: "Privacy is a concept with far reaching implications, absolutely untranslatable into Russian or into the languages of the other 15 republics of the Soviet Union. It would be unfair to ascribe the lack of this concept solely to living conditions in the Soviet era, though, needless to say, communal apartments where from 4 to 10 families share a bathroom, dormitories and the thin-walled barracks where a few generations lived their lives, as well as the overcrowding in today's urban dwellings, did 
and do little to foster the introduction of that concept into our daily experience" (Lourie, Mikhalev 1989:38).

In the conditions of the Soviet Union the divergence of concepts that reflects the spirit of the nation, the specifics of thinking and the nature of perceiving reality by representatives of different linguocultures, can lead to the attempt of comprehending the other culture through one's own concept sphere and by doing so provoke situations of lack of understanding. The conflict of concepts formed in different "hypertexts," on the intersection of different meanings and associations, leads to delusions with respect to one another as a result of the defeated expectancy effect.

Coming to Armenia, Americans often try to find their "network of coordinates" to analyze the phenomena of our life. For example, in grant competitions American organizations have Armenian participants fill out forms and evaluate the level of their professional competence through the prism of concepts widely spread in the American society, but not well-known to Armenians. That is why key American concepts such as pluralism and diversity often become a stumbling block for Armenian participants, who are not able to relate their own experience with concepts of another culture.

A person who is not familiar with concepts of another culture does not experience inconvenience because of it. The study of lexis and grammar of a new language is not necessarily accompanied with mastering new concepts. In the opinion of A.A. Zalevskaya "When perceiving a new foreign language unit, a bilingual individual is inevitably trying to "adjust" the denotations of the correlative words in the contacting languages" (1978:72). The mastery of the concept sphere of a foreign language signifies a qualitatively new level of cultural-linguistic competence of an individual, the beginning of the existence of two linguocultures in "parallel worlds." Great experience is required for an individual who appears in new cultural surroundings to "synchronize" his/her concepts as mental formations with the mental formations of the interlocutor - a bearer of given linguoculture.

\section{References:}

1. Cambridge International Dictionary of English. (1995) Cambridge: Cambridge University Press.

2. Karasik, V.I. (1996) Kulturnye dominanty v yazike. // Yazikovaya lichnost. Kulturnye koncepty. Volgograd: Peremena.

3. Life and Culture of the USA. (2002) Stanford: Stanford University Press.

4. Lourie, R., Mikhalev, A. (June 1989) Why You'll Never Have Fun in Russian. // New York Times Book Review.

5. Malxhasiants, S. (1944) Hajeren bacatrakan bararan. Yerevan: Hajkakan SSR Petakan Hratarakchutjun.

6. Shejga, E.I. (2000) Semiotika politicheskogo diskursa. Volgograd: Peremena.

7. Zalevskaja, A.A. (1978) Ob eksperementalnom issledovanii struktury yazikovogo znaka v usloviaxh bilingvizma. // Psixholingvisticheskie i lingvisticheskie problemy yazikovixh kontaktov. Kalinin: KGU. 


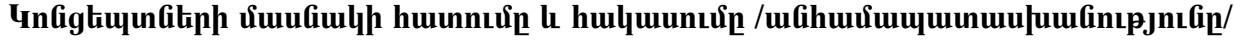

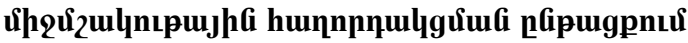

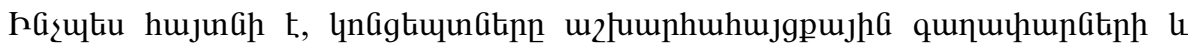

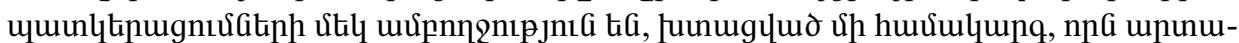

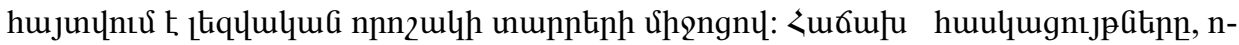

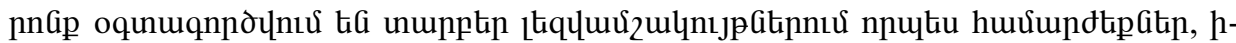

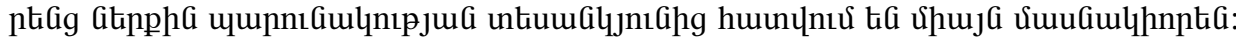

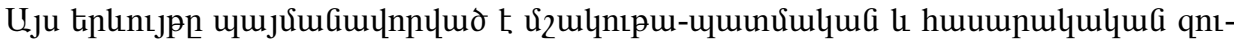

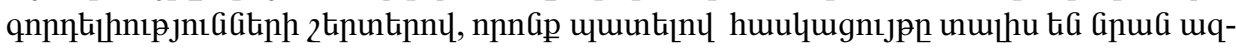

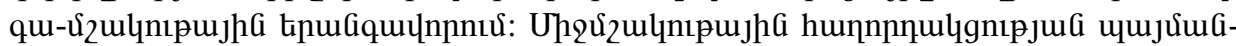

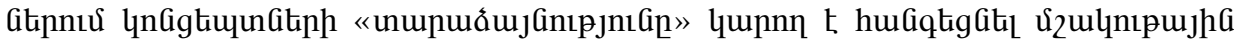

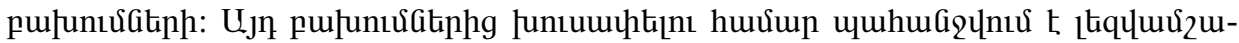

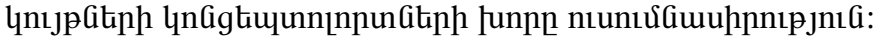

